\title{
Analysis on the Driving Effect of Chinese Fiscal Expenditure on Economy
}

\author{
Yijuan Zhang ${ }^{1, *}$ \\ ${ }^{1}$ School of Economics, South China Business College, Guangdong University of Foreign Studies, Guangzhou, \\ Guangdong, China \\ *Corresponding author. Email:1574285616@qq.com
}

\begin{abstract}
Fiscal expenditure is one of the important means for the government to regulate and control the macro economy. In different economic development cycles, adopting different fiscal expenditure policies will produce different expenditure effects. The fiscal expenditure policy needs to be optimized to clarify its role in driving economic growth. Therefore, proper fiscal expenditure control is a necessary prerequisite for promoting high-quality growth of the Chinese economy. This paper uses the "IS-LM" theoretical model as the theoretical basis, starting with the multiplier effect of fiscal expenditure and output elasticity. It selects the data related to China's fiscal expenditure and economic growth from 2000 to 2019 to analyze and study the driving effect of China's fiscal expenditure on the economy. Studies have shown that stable fiscal expenditures are conducive to ensuring stable economic growth, and show a certain multiple relationship. In addition, this paper proposes to give full play to the sustainable effect of finance on the economy, and finally puts forward corresponding countermeasures and suggestions.
\end{abstract}

Keywords: fiscal expenditure, economic growth, driving effect

\section{INTRODUCTION}

How to ensure high-quality economic growth is currently a major research issue in the academic world, but there are many factors that affect economic growth. Only by identifying the factors that have the greatest impact on economic growth and analyzing the specific effects of these factors on economic growth can it be possible to find ways to promote economic growth. In terms of the major factors affecting economic growth, it is not difficult to know from the existing research literature that fiscal expenditure has a certain impact on economic growth. However, there are no clear conclusions about the impact of fiscal expenditure on economic growth, whether the impact is obvious, and whether the impact on economic growth is the same in different stages.

As the largest developing country, China has made extensive explorations in promoting economic growth. The national government attaches great importance to the use of fiscal expenditure tools to carry out macrocontrol of the economy. As the world economy gradually declines and falls into crisis, the important reason for China to maintain high economic growth is that it comes from growing fiscal expenditures. According to statistics from the Ministry of Finance, China's total fiscal expenditure in 2019 has reached 23.89 trillion yuan, but China's total economic output that year was 9.9 billion yuan, accounting for $24.11 \%$ of the total economic output, an increase of nearly $10 \%$ compared to 2000 . Total expenditure rose by more than 20 trillion yuan, and it still maintained a high growth rate. At the same time, China's economic growth rate is higher than the global average growth rate every year. It can be initially seen that fiscal expenditure has a certain stimulating effect on economic growth.

Some achievements have been made in the academic world on the relationship between China's fiscal expenditure and economic growth. Jiang Yuyan (2020) conducted a separate analysis of Guangdong Province. She believes that in different times and different regions, Guangdong Province's fiscal expenditures have different stimulating effects on economic growth, but in general, fiscal expenditures can greatly promote economic growth. When Jia Tianyue (2020) analyzed Anhui Province, he found that fiscal revenue and expenditure have completely opposite effects on economic growth. Fiscal revenue is a negative pull, while fiscal expenditures are a positive pull, and the size of the pulling effect changes closely with the intensity of the fiscal policy. Wang Yan (2020) believes that the pulling effect of fiscal expenditure on economic growth is greatly affected by the financial environment at that time. When the financial environment develops relatively well, increasing fiscal expenditure will not promote economic growth, but 
when the financial environment is deteriorating, increasing fiscal expenditure can greatly promote economic growth. Nijkamp and Poot (2004) elucidate fiscal collection is conducive to the government to increase investment in infrastructure construction and public facilities construction, which is conducive to the future development of the economy, and the promotion effect of economic growth will be enhanced with the extension of time.

In addition to the above scholars' analysis of the effects of fiscal expenditures in various regions of China on the economic growth traction, other scholars have focused on analyzing the relationship between education fiscal expenditures, national defense fiscal expenditures, scientific fiscal expenditures and other detailed fiscal expenditure items and economic growth, making important contributions to this academic research field.

In general, whether from the academic or from the current actual situation in China, it is necessary and significant to study the pulling effect of fiscal expenditure on the economy, which can give full play to the macro-control functions of fiscal policy on the economy, and ultimately promote high-quality economic growth in China.

\section{CHINA'S FISCAL EXPENDITURE AND ECONOMIC DEVELOPMENT STATUS}

\section{A. Current fiscal expenditure}

Fiscal expenditure, as one of the most important tools for the Chinese government to carry out macroeconomic regulation and control, has always been one of the most frequently used macroscopic policies by the Chinese government.

In terms of total amount, China's total fiscal expenditure has been increasing since 2000. In 2000, it was 1.59 trillion yuan. By 2019, it had risen to 23.89 trillion yuan, an increase of more than 20 times.

From the perspective of growth rate, the growth rate of total fiscal expenditure has been maintaining a relatively high growth rate, with an average annual growth rate of more than $10 \%$, and it can be divided into two more obvious stages. The first stage is expressed as before 2008. During this stage, the change in the growth rate was constantly rising. In 2008, it rose to the highest level of $25.74 \%$, which far exceeded the growth rate of the economic aggregate in the same period. The second stage is from 2009 to present. After the growth rate reached its peak in 2008, the growth rate fell sharply in 2009 , and it dropped by $4 \%$ that year. Although there was a recovery in 2011 and 2015, the growth rate was much lower than in 2008. By 2019, the growth rate had dropped to $8.13 \%$, which was basically the same as the economic growth rate that year. ("Fig. $1 ")$

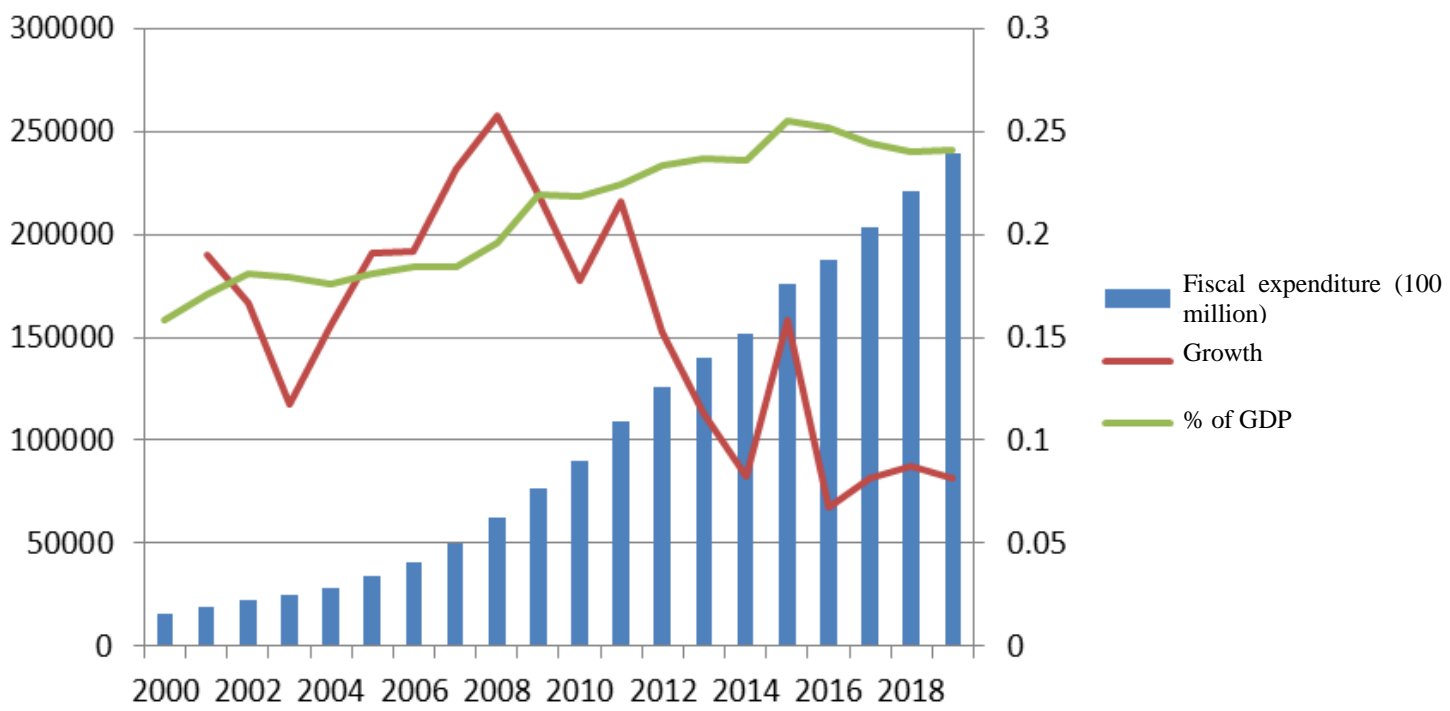

Fig. 1. China's fiscal expenditure growth status from 2000 to 2018.

From the perspective of the proportion of total GDP, it can be clearly seen that the proportion of fiscal expenditure has been rising since 2000, and has only a. Data source: National Bureau of Statistics declined in a few years, but the decline is very small. In 2000 , the fiscal expenditure accounted for $15.84 \%$ of GDP. By 2019, the proportion rose to $24.11 \%$, and the 
proportion increased by nearly $10 \%$, which can reflect the rapid growth of fiscal expenditure.

From the perspective of the specific subdivision of fiscal expenditures, education expenditures accounted for the largest proportion of China's fiscal expenditures in 2019 , as high as $14.62 \%$. It can be seen that the state attaches importance to education. The second was social security expenditure, accounting for $12.38 \%$, and the third was community affairs expenditure, accounting for $10.75 \%$. ("Table I")

TABLE I. SUBDIVISION OF CHINA'S GOVERNMENT EXPENDITURE ITEMS IN 2019

\begin{tabular}{|c|l|l|}
\hline Project & Amount (100 million) & Proportion (\%) \\
\hline General public service expenditure & 20687.5 & $8.66 \%$ \\
\hline National defense expenditure & 12117.4 & $5.07 \%$ \\
\hline Education expenditure & 34913.04 & $14.62 \%$ \\
\hline Science and technology expenditure & 9528.54 & $3.99 \%$ \\
\hline Social security expenditure & 29580.37 & $12.38 \%$ \\
\hline Medical and health expenditure & 16796.77 & $7.03 \%$ \\
\hline Environmental protection expenditure & 7443.57 & $3.12 \%$ \\
\hline Community affairs expenditure & 25681.15 & $10.75 \%$ \\
\hline Agriculture, forestry and water conservancy expenditure & 22420.11 & $9.39 \%$ \\
\hline Transportation expenditure & 11412.68 & $4.78 \%$ \\
\hline
\end{tabular}

Data source: National Bureau of Statistic

\section{B. Current economic growth}

As the world's largest developing economic entity, China's economic growth rate has been higher than the global average growth rate since entering the 21 st century. China's total GDP in 2000 was only 10 trillion yuan, and by 2019 it had reached 99 trillion yuan, successfully becoming the world's second largest economic entity. Its gap with the world's largest economy, the United States, narrowed to 7 trillion U.S. dollars. Relevant economists predict that by 2030,

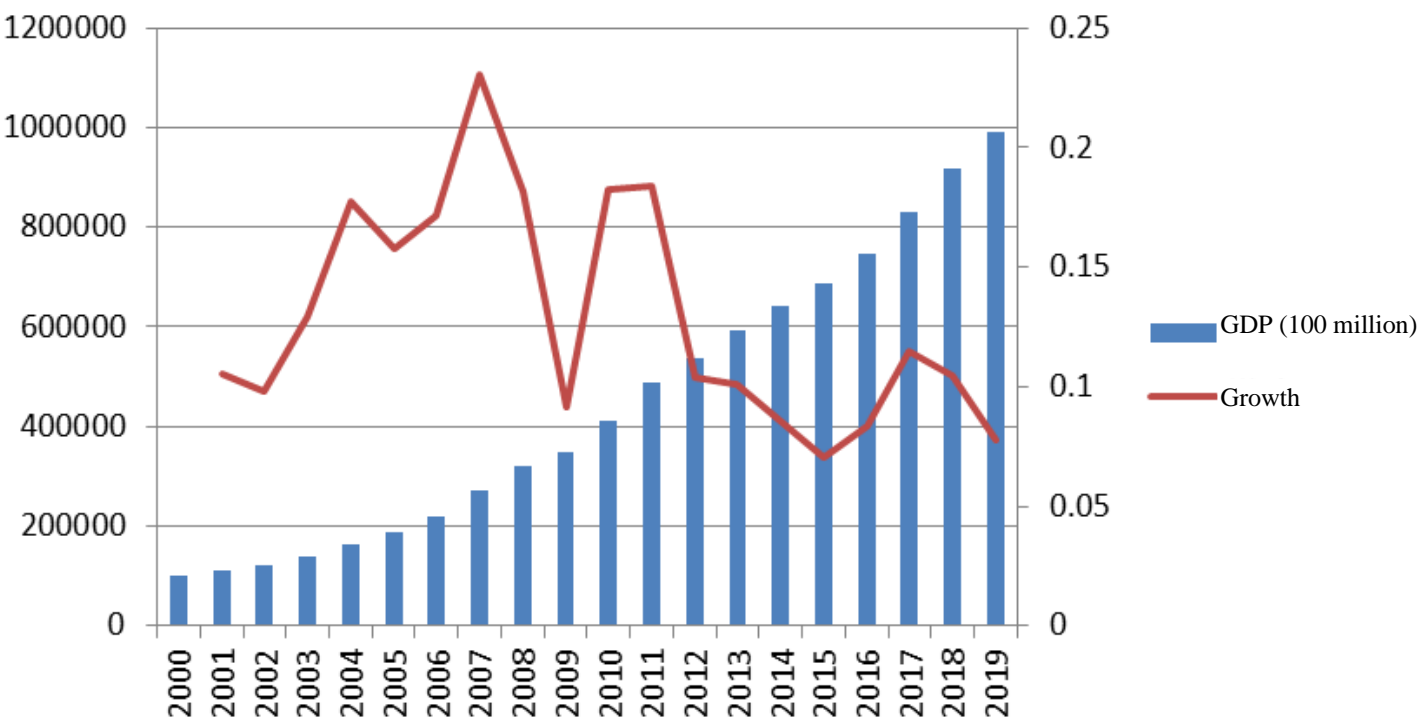

China's total GDP will catch up with the United States, and it is expected to become the world's largest economic entity.

According to the growth rate, the growth rate of China's GDP is roughly in line with the growth rate of fiscal expenditure. The year of 2008 can still be used as the dividing line. Before 2008, China's GDP growth rate increased year by year. After 2008, the growth rate declined, and gradually maintained a relatively stable trend. Until 2019, the growth rate was 7.79\%. ("Fig. 2")

Fig. 2. China's economic growth since 2000.

Although China's economic aggregate has maintained a good growth momentum since 2000, it doesn't reflect the quality of economic growth. From the perspective of industrial structure, the changes in China's three major industries since 2000 have been
Data source: National Bureau of Statistics very obvious. In particular, the proportion of the primary industry in the industrial structure has dropped significantly. In addition, there is the competition between the secondary and tertiary industries. In 2013 and before, the secondary industry accounted for the 
largest proportion in China's industrial structure, but after 2013, the industry with the largest proportion became the tertiary industry, and the optimization and

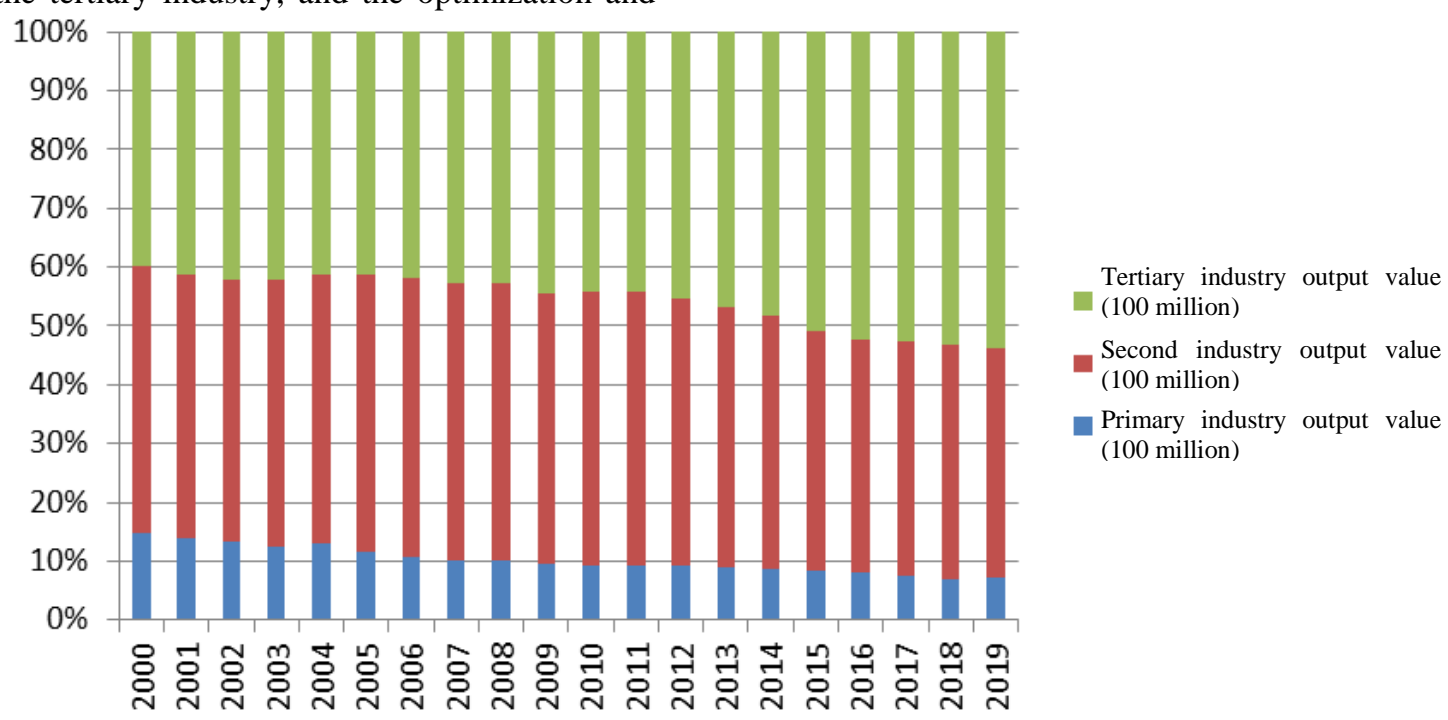

upgrading of the industrial structure was obvious. ("Fig. 3")
(100 million)

(100 million)

Primary industry output value

(100 million)

Fig. 3. Changes in China's industrial structure since 2000.

\section{ANALYSIS ON THE EFFECT OF CHINESE FISCAL EXPENDITURE ON ECONOMIC TRACTION}

This paper studies the driving effect of fiscal expenditure on the economy, which is mainly measured by fiscal expenditure multiplier and fiscal output elasticity.

\section{A. Analysis of fiscal expenditure multiplier}

The fiscal expenditure multiplier comes from the "IS-LM" model. The so-called fiscal expenditure multiplier is the influence multiple of the change in the total economic volume when the fiscal expenditure increases, which can more intuitively reflect the influence of fiscal expenditure on economic growth.

The formula is as follows:

Fiscal expenditure multiplier $=$ GDP growth $/$ fiscal expenditure growth

After calculation, the following results are obtained:

Since 2000, China's fiscal expenditure multiplier has changed significantly and fluctuated fiercely, but the overall fluctuation has been around 4 times. In 2001, the fiscal expenditure multiplier was 3.5. In 2019, the fiscal expenditure multiplier was 3.98 , a relative increase of 0.48 times. It can be seen that since 2000, the role of fiscal expenditure in stimulating the economy has increased, that is, in 2019, the stimulus multiple of fiscal expenditure on the economy was 3.98 times. Since 2000, the average of the fiscal expenditure multiplier has been 4.28 , indicating that China's fiscal expenditure has driven the economy by 4.28 times. However, it was only 3.98 times in 2019 , reflecting that the effect of transforming fiscal expenditures into the economy in 2019 was poor and lower than the average. ("Fig. 4") 


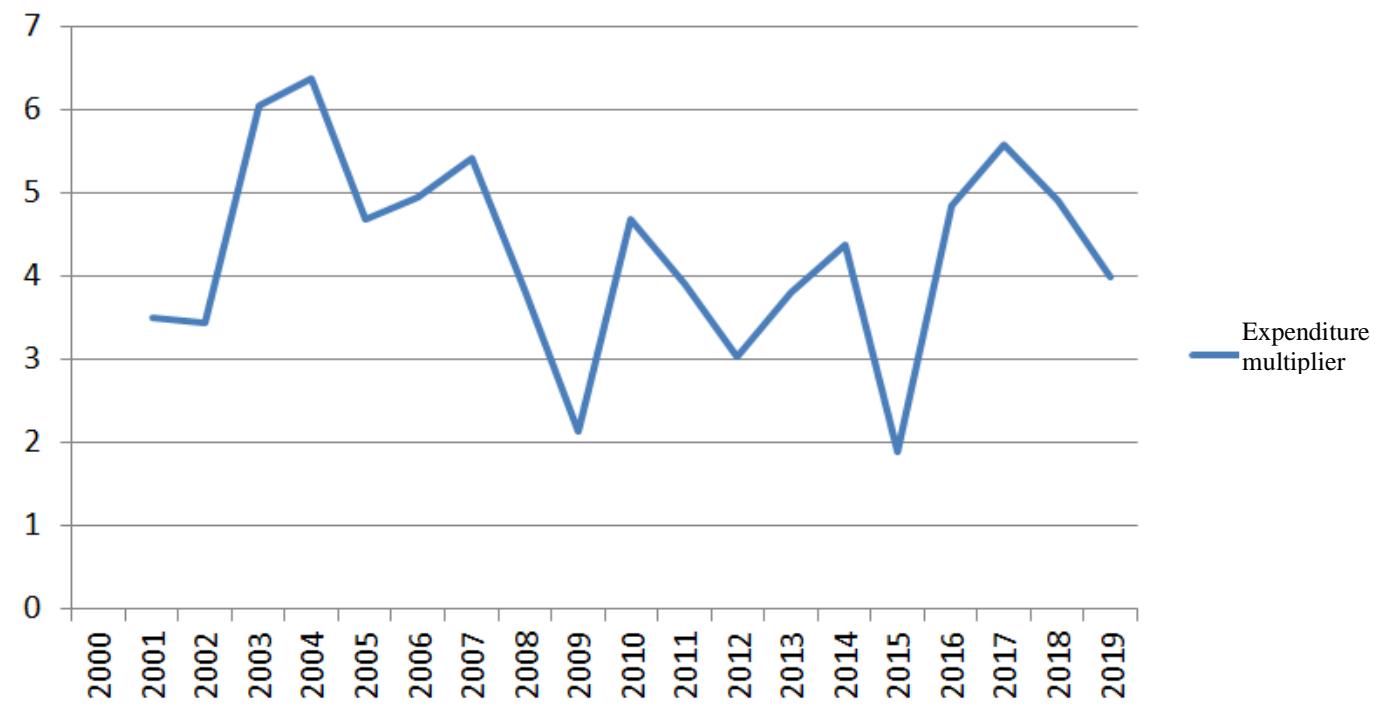

Fig. 4. Changes in the fiscal expenditure multiplier since 2000.

In all the above years, the fiscal expenditure multiplier for the three-year period of 2001, 2009, and 2015 was significantly lower than that of other years. The three-year fiscal expenditure multiplier was 3.5 , 2.14 , and 1.88 respectively. The lowest was 2015 , which was nearly 3 times lower than the average. It can be seen that in 2015, the utilization efficiency of fiscal expenditure was relatively low, and the driving effect of fiscal expenditure on the economy was far from being fully utilized.

In addition, the fiscal expenditure multipliers in 2003, 2004, and 2017 were 6.05, 6.36, and 5.59 respectively, which were significantly higher than other years, and even far higher than the average. It can be seen that the maximum effect of fiscal expenditure utilization efficiency in these three years was relatively obvious, and the state fiscal expenditure was well transformed into the driving force on the economy.

\section{B. Analysis of output elasticity coefficient of fiscal expenditure}

According to the output elasticity measured by fiscal expenditure, fiscal output elasticity is a direct economic benefit indicator that comprehensively reflects all fiscal expenditures, and can measure the contribution of fiscal expenditure to the increase in output.

The formula is as follows:

The output elasticity coefficient of fiscal expenditure = GDP growth rate / fiscal expenditure growth rate

After calculation, the following results are obtained:
Data source: National Bureau of Statistics

Since 2000, the output elasticity of China's fiscal expenditure has generally shown a slow rising trend, indicating that fiscal expenditure's role in driving the economy has gradually become greater. And since 2000, the output elasticity has been positive, indicating that the driving effect of fiscal expenditure on the economy is a positive driving effect. The output elasticity in 2000 was 0.56 . By 2019 , the output elasticity rose to 0.96 , an increase of 0.4 , with a large increase, indicating that the driving effect of fiscal expenditure on the economy increased significantly. Since 2000, the average elasticity of output has been 0.89 , which is relatively high. ("Fig. 5") 


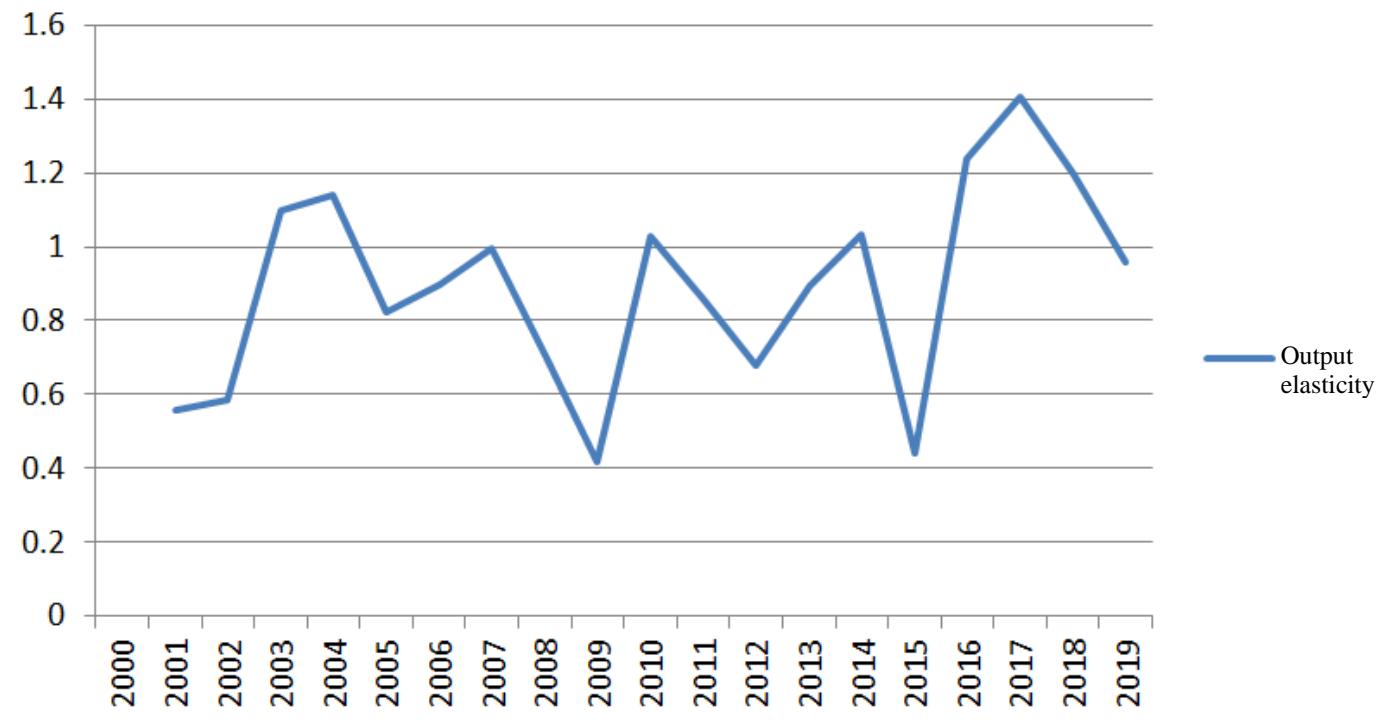

Fig. 5. Changes in China's fiscal expenditure output elasticity since 2000.

The changes in output elasticity and the expenditure multiplier are relatively consistent. The relatively lowest three years occurred in 2001, 2009, and 2015, and the output elasticity were $0.56,0.42$, and 0.44 , respectively, which were significantly lower than the average level of 0.89 . The phased high spot of output elasticity was also consistent with the expenditure multiplier. The output elasticity itself was a supplementary explanation to the expenditure multiplier. Therefore, it can be concluded that China's fiscal expenditure has a more obvious driving effect on the economy. The average expenditure multiplier is 4.28 , and the average output elasticity is 0.89 .

\section{CONCLUSION}

This paper selects the latest data on China's fiscal expenditure and economic growth, and uses the expenditure multiplier and output elasticity in the "ISLM" model to jointly measure the driving effect of China's fiscal expenditure on economic growth. In the end, it is found that the driving effect of fiscal expenditure on the economy fluctuates by about 4 times. The output elasticity and the expenditure multiplier together prove the multiple driving effect of fiscal expenditure on the economy. In addition, there are obvious time differences in the driving effect of fiscal expenditure on the economy, and the driving effect is different in different years.

Against the backdrop of the downward trend in the world economy and increasing pressure to maintain stability, China must give full play to the driving effect of fiscal expenditure on the economy to ensure stable and high-quality economic growth.
First, the expansion of fiscal expenditures needs to be moderately controlled. The state can determine a reasonable level of fiscal expenditure according to the cycle stage of economic development, and moderately control the expansion of fiscal expenditure. Now, it's necessary to unswervingly adhere to the implementation of supply-side structural reforms, especially control financial investment in industries with excess capacity, and strive to promote industrial transformation and upgrading.

Second, the structure of government fiscal expenditures needs to be optimized. Fiscal expenditures should highlight key points and make overall plans, gradually withdraw from the competitive investment field, appropriately increase the proportion of social, cultural and educational expenditures and economic construction expenditures, maintain expenditure on social public facilities and basic facilities, vigorously promote and extensively give play to the enthusiasm of all sectors of society to participate in the construction of social people's livelihood, increase investment support for high-risk industries and high-tech industries, and maintain the steady development of non-profit sectors related to the country's economic development.

Third, it is necessary to support the development of backward areas and increase the marginal utility of fiscal expenditures to achieve balanced development of the regional economy. At the same time, the scope of fiscal expenditure should be scientifically delimited. According to the objective requirements of the socialist market economy system and the transformation of government functions, it's needed to scientifically delimit the scope of fiscal expenditure, reasonably determine the items of fiscal expenditure, strictly 
enforce economic discipline, and strengthen the construction of the financial system.

\section{References}

[1] Jia Tianyue, Zhu Jianwen. Research on the Economic Growth Effect of Fiscal Policy - Taking Anhui Province as an Example [J]. Journal of Science of Teachers' College and University, 2020,40(04):34-38. (in Chinese)

[2] Jiang Yuyan. The Economic Growth Effect of Guangdong's Fiscal Expenditure [J]. Journal of South China Agricultural University (Social Science Edition), 2020,19(03):105-114. (in Chinese)

[3] Li Changzai. The Impact of the Scale and Structure of Local Government Fiscal Expenditures on Economic Growth [J]. China Circulation Economy, 2020(08):107-108. (in Chinese)

[4] Li Mei. Analysis of the Relationship Between Fiscal Expenditure and Economic Growth [J]. Chinese \& Foreign Entrepreneurs, 2020(10):81-82. (in Chinese)

[5] Wang Yan, Wang Jihong. The Nonlinear Effect of the Scale of Financial Expenditure on Economic Growth - An Empirical Analysis Based on Provincial Panel Data [J]. Quantitative Economics Research, 2020,11(02):18-32. (in Chinese)

[6] Nijkamp P, Poot J . Meta-analysis of the effect of fiscal policies on long-run growth[J]. European Journal of Political Economy, 2004, 20(1):91-124 